Please note the final published version is available at:

http://www.ingentaconnect.com/content/tpp/jpsj/2010/00000018/00000002/art00007

\title{
Cultural Services and Social Policy: Exploring Policy Makers' Perceptions of Culture and Social Inclusion
}

Vikki McCall, University of Stirling

\section{Abstract}

In post-devolution Scotland, New Labour added to the role of 'culture' by introducing ideas of social inclusion to policies concerning cultural services. Ten years later, with the SNP minority government in the Scottish Parliament, do policy makers think social inclusion still has a role within cultural services? This paper shows policy makers' understandings of 'culture' and social inclusion are vague, general and complex. This has encouraged policy makers to think of cultural services as resources to fulfil wider economic and social objectives. At the same time cultural services are placed at an individual level, with cultural services seen as "generators of wellbeing", rather than agents of social change. Social inclusion and cultural meanings are linked to individualistic causes of poverty and related to the SNP's economic focus in Scotland. This complexity impacts on the interpretation and implementation of policy and has resulted in the cultural agenda being seen as less of a priority within the new SNP administration. 


\section{Introduction}

Policy concerning the arts in the UK has historically been created with an 'arms-length principle', which has aimed to allow the arts sector to create and implement policy independently from government influence. This has been aimed to minimise political motivations within cultural services (Boylan 1988). This is shown through the power and funding given to politically neutral organisations such as Arts and Museum Councils. Despite this, Gray (2007: 203) shows that cultural and arts policies have been increasingly justified by their 'attachment' to other sets of policy concerns in an instrumental fashion. Increasing attention given to the arts and cultural institutions within the UK since 1999 has helped create a new role for culture, linking it to aspects of social inclusion and challenging the boundaries of traditional welfare provision. This paper explores policy makers' ideas surrounding social inclusion and cultural services. It highlights how individual perceptions of culture and social inclusion can be linked to understandings of structural and individualistic causes of poverty. It also shows that the role of the cultural services, especially museums, is linked to the generation of wellbeing by certain policy makers in Scotland.

The idea of using 'the arts' and cultural services such as museums to create social change is relatively new, and has been a neglected area in mainstream social policy analysis. Sandell $(1998,2002,2003)$ is among the minority in focusing on this, having explored the potential of museums in becoming agents of social inclusion, specifically their potential as instruments for positive social change and community cohesion. Although promoting the social role of museums is not new to museum professionals, after the devolution of the Scottish Parliament in 1999, Scottish New Labour started to add social inclusion to their cultural policy objectives, stating that arts, sports and leisure facilities all had a role in tackling social exclusion as "they can help to increase the self-esteem of individuals; build community spirit; increase social interaction; improve health and fitness; create employment; and give young people a purposeful activity, reducing the temptation to anti-social behaviour" (Scottish Office 1999: 4.34). For cultural services in particular, the National Cultural Strategy $(2000,2001,2002,2003)$ identified development opportunities to include disadvantaged groups and highlighted actions to help 
promote "culture's potential contribution to education, promoting inclusion and enhancing people's lives" (Scottish Executive 2000). After 2007, however, the new administration led by the Scottish National Party has introduced new economically focused policy directions to Scotland.

The increase of political attention has coincided with increasing concern about the definitions and concepts used within policy. Gray (2006) argues that one definition of culture shall never suit everyone, including policy makers. The same can be argued with the concept of social inclusion within cultural services, especially museums (see Newman and McLean 2004; Tlilli 2008; McCall 2009 for example). What this paper shows is that due to this complexity some policy makers express their understanding by focusing on the instrumental role of cultural services, especially their potential impact on tackling social problems. The vagueness of current policies has led to policy makers expressing views based on their ideological ideas on the causes of poverty, which they see as linked to the social inclusion and cultural agenda in Scotland. This paper discusses ideas of culture, cultural services and social inclusion within academic literature before going on to explore their significance and role from Scottish policy makers' perspectives.

\section{Ideas of Culture and Cultural Services}

The introduction suggested an increasing interest in using cultural services to fulfil policy agendas. The idea and meaning of culture and cultural services, however, remains underdeveloped within policy in the UK. This paper cannot give an in-depth explanation of culture, only show the beginnings of its complexity and the challenges this brings to the cultural sector. Indeed, there are currently competing definitions and understandings of the role of culture and cultural services between international, European and UK policy. That culture is complex is not a new issue, having been discussed in social policy since the nineteenth century, embodying many different connotations and meanings (Clarke 2004). Culture has increasingly become a resource in political and policy struggles, while 'cultural identities' have become associated with equal access to income, health, housing and employment (as opposed to sex, gender, race, sexuality) (Ross 1998: 191). These political and policy concerns have impacted on cultural 
services by directing them to fulfil goals and objectives other than cultural ones (Vesthiem 1994). This in turn has created tension due to an increasing pressure to meet political targets (West and Smith 2005) and has impacted a wide range of services.

Although there are many kinds of cultural services, Scottish government policy refers to the arts, literature, theatre, local cultural traditions, craft, community facilities, festivals, museums, local heritage, libraries, local archives, cultural enterprise support and more (Draft Culture (Scotland) Bill 2006). The cultural services referred to in this paper particularly centre on services such as museums, galleries and local heritage.

Further to the various types of services, culture itself has varying definitions within policy. Belfiore and Bennett (2007: 2) show that although cultural policy literature has an implied understanding of 'arts' and 'culture', there are underlying competing definitions which range from European high culture, to discourse on cultural diversity, elitism, popular culture and government definitions. In the National Cultural Strategy (2000: 4) the government defined culture in line with the UNESCO (2002) definition as:

the set of distinctive spiritual, material, intellectual and emotional features of society or a social group, and that it encompasses, in addition to art and literature, lifestyles, ways of living together, value systems, traditions and beliefs.

They also added a broader stance addressing 'cultural services' such as museums, the arts, heritage resources, libraries and archives (Scottish Executive 2006). However, the word 'culture' appears to have varying interpretations through the draft bill and draft guidance and is defined in reflective terms. Local authorities and the cultural institutions consulted called for a more detailed definition of 'culture' (Scottish Executive 2007: 18, SMC 2003). This shows that cultural services need further understanding of what policy makers mean by culture to implement policy effectively.

\section{Culture as reflective or culture as instrumental}

In the above account, culture is seen to be reflective (Hooper-Greenhill 2000: 13) and not instrumental. Thus the Scottish Government define culture as something that is produced by 
and reflects (or mirrors) society, not something that can be used to create change. This poses a problem for social inclusion policy as it aims to utilise these cultural elements and measure its impact on certain areas and people in society.

The reflective definition (which suggests a reactive idea that can only be understood as reflecting, not changing society) does not account for the more actionable role of culture that is sometimes used within social policy. Instead, culture is more accurately defined as constitutive, where "cultural symbols have the power to shape cultural identities at both individual and societal levels; to mobilise emotions, perceptions and values; to influence the way we feel and think. In this sense, culture is generative, constructivist" (Hooper-Greenhill 2000: 13). Clarke (2004: 33-39) describes this division as "culture as practice", focusing on the effect of social policy on culture, and "culture as property" where practices and behaviours are steered by cultural patterns, something individuals belong to and which belongs to them. This is central to understanding the role policy makers' perceive culture to have in related policies. The generative and reflective understandings of culture generates interesting questions over how culture can (or not) be used for social policy goals, given that it is such a diverse and complex concept.

\section{Ideas of Social Exclusion and Social Inclusion}

The concept of culture becomes further complicated as it is coupled with the ambiguous concepts of 'social inclusion' and 'social exclusion'. The interpretation and complexity can impact on the cultural sector in different ways. In the beginning, social exclusion was very much linked to ideas around poverty (Baldock et al. 2007). While poverty generally focuses on distributional issues and lack of resources, social exclusion centres on relational issues, inadequate social participation, lack of social integration and power (Room 1995: 5). These issues are most evident among certain groups such as disabled people, lone parents, the unemployed, young adults and can have influence at a global, national, local, community, family and finally individual level (Burchart et al. 2002: 1). This makes social exclusion associated with but distinct from poverty and from economic inequality (Barry 2002). Indeed, social exclusion is more closely linked to social solidarity and social cohesion, which bind citizens together 
(politically, socially, economically and morally) (Williams 1998, Silver 1994). The academic definitions show that concepts of social inclusion and exclusion are wide, multi-dimensional and contested.

Further to the academic understanding of social exclusion, the political definition of social exclusion and inclusion can determine and influence the scope of policy responses (PercySmith 2000:15). Within UK policy, social exclusion is referred to as:

a shorthand label for what can happen when individuals or areas suffer from a combination of linked problems such as unemployment, poor skills, low incomes, poor housing, high crime environments, bad health and family breakdown (Scottish Office 1999: 2.1).

Although this was a UK wide policy definition, New Labour in London worked to a social exclusion definition, while Scottish New Labour has had a social inclusion focus in their policy directives and actions. This focus goes beyond targeting groups of people, which social exclusion tends to do, to tackling barriers to inclusion such as poor health, homelessness, crime, a criminal record, drug misuse and prostitution (Scottish Office 1999).

The concepts are further complicated as social exclusion and inclusion take different meanings "from context to context within political rhetoric and in academic and professional discourses" (Sandell 1998: 401-418). Implementation of corresponding social policies would be difficult as a result and analysis of social exclusion and its relevance to policy "is hindered because the terms, concepts and associated language in relation to the arts, heritage and the wider cultural sector remain undeveloped" (Sandell 1998: 401-418). This has generated many problems for the cultural sector, which Gray (2006: 102) lists as:

- The absence of a clearly defined area of action;

- A lack of political significance for the cultural policy sector;

- The fragmented organisational universe that it operates within;

- The variation in geographical scale that it operates within; and

- The effectively reactive, rather than proactive, nature of policy development that it involves. 
These problems can directly affect formation and implementation of policy in many ways, including the individualisation of policy (Gray 2000, 2006). These arguments indicate is that social inclusion is a complicated and inherently political concept, where the meaning given by policy makers makes an impact on social policy and its implementation. For museums, problems include lack coherence and clarity in relation to social inclusion policy, while at the same time a quite strong advocacy from policy makers (Newman and McLean 2004). This calls for an in-depth look at the meaning given to social inclusion through interviews with policy makers to explore the impact on services subject to these different meanings and understandings.

\section{Scottish Government Policy}

The complexity of culture and social inclusion, shown above, has been reflected in the policies concerning the cultural sector. The sector is complex, becoming much more 'policy-driven', which has revised the relationship between the cultural sector (in particular museums) and the government (Tlili 2008: 125). In 1999 the structure of the UK government changed dramatically due to the devolution of certain powers to a newly formed Scottish Parliament and Welsh Assembly. The Scottish parliament has been granted powers over education, justice, health and cultural policy. Since its creation, Scottish New Labour dominated the political arena in Scotland as well as the UK. In 2007, however, the Scottish National Party (SNP) took over with a minority government, transforming the Scottish administration (previously known as the Scottish Executive) into the Scottish Government. This has influenced the strategic direction and focus for Scottish social policy under the overall aim "to focus the Government and public services on creating a more successful country, with opportunities for all of Scotland to flourish, through increasing sustainable economic growth." (Scottish Government 2007: vii). Regarding terminology, the SNP proposed to change all Labour 'buzz words' such as social justice and social inclusion (Hutcheon 2008). These would be replaced with concepts around cohesion, solidarity and sustainability, which all have an economic basis (Scottish Government 2008). For example 'cohesion' is about narrowing the gap in economic activity, reducing geographical inequalities, regenerating areas of depravation and promoting over equity (Scottish Government 
2008). Furthermore, 'solidarity' aims "to increase overall income and the proportion of income earned by the three lowest income deciles as a group by 2017", showing that these concepts are indeed linked to improving economic sustainability (Scottish Government 2008: 2). Within these targets, local authorities were given fifteen outcome measures, none of which focused on culture or cultural services. This would suggest that social inclusion and cultural policies may be affected by the proposed changes in strategic outcomes within Scotland, making a large impact on Scotland's future direction in this area.

\section{Research Stance}

Inspired by the above literature, the study explored how ideas of culture and social inclusion are treated in policy-making and its application. The research questions were: How do policy makers' perceptions of culture relate to social inclusion policy and its perceived role within cultural services? What is the meaning and significance of the social inclusion agenda for policy makers in relation to cultural services?

To tackle the research questions and explore policy makers' perspectives on culture and social inclusion policy, sixteen qualitative, semi-structured interviews were conducted. By focusing on policy makers' perspectives, this research took a constructionist approach, where social reality was viewed as being created from the actions and interpretations of participant's interactions (Becker and Bryman 2004). In this way, the research does not present 'objective reality' but what can be known through the interpretation of social exchanges, language, relationships and social functions (Flick 2006). Those who participated were involved in cultural and social policy formation on some level. Four SNP and four New Labour MSPs, six civil servants (referred to as CS in the findings, including three quasi-civil servants linked to cultural organisations), and two stakeholders in other cultural bodies (CBs) were interviewed. No particular area of Scotland was represented as participants involved worked on a mostly Scotland-wide scale.

This research was essentially 'data-driven' (Silverman 2005) and analysis of the interview transcripts occurred through a step-by-step process that enabled the researcher to be immersed in the data, utilizing a mix of manual and computer based methods to ensure a fully rounded interpretation. Limitations of the research include the small sample size and lack of 
representation from other parties beyond the SNP and New Labour. Access, resource and time constraints created a need to prioritise participants by relevance. Given the importance of cultural organisations and civil servants in the policy making process (Hill 1997), we focused on New Labour and SNP MSPs who hold the majority of places within the Scottish Parliament's Education, Lifelong Learning and Culture Committee. Confidentiality and anonymity issues were faced due to the small sector in question and the potential harm to participants in the public arena, requiring some contextual information to be left out of the paper. The reliability of responses were questioned to see if participants were only stating the party line, but similarly to Bochel and Defty (2007), MSPs' internal values often reflected their parties, giving some consistency between opinions. Finally, the findings cannot be generalised and, although this is not the aim of the research, further analysis of policy makers throughout the UK would create very interesting comparisons.

\section{Findings: The Meaning and Significance of Social Inclusion in the Cultural Sector}

The following findings show policy makers' understanding of social inclusion, the positive and negative implications for cultural services and the different terminologies used to represent social inclusion. It should be noted, however that the following findings are from a small sample of policy makers within the Scottish government. This gives more depth to the topic, but is in no way representative. The findings from these participants and their understandings of social inclusion are insightful as to how they place cultural services in the policy agenda.

\section{Social Inclusion within an Economic Focus}

The meaning of social inclusion and it's placement within the SNP agenda are firstly explored. Participants were asked what they felt social inclusion meant, and responses were linked to a cultural context. Evidence suggests that some policy makers view social inclusion as old terminology as "someone once said to me, oh social inclusion that's an old-fashioned term now" (CS2) and the SNP are "saying that em, we would like to use language that is more accessible to the person in the street" (CS1). Concepts such as 'fairness' (SNP4), 'resilience' (CS1), 'social engagement' (CS2) and 'socially engaged practice' (CS3) were more dominant within 
participant rhetoric. Similarly to Tlili's (2008) findings of museum professionals' understandings of social inclusion, policy makers' were also surprised to be asked the meaning of social inclusion and found it difficult to formulate a clear meaning. This confusion over the meaning of social inclusion mirrors the current, non-specific policy documents.

Interestingly, the SNP vision of sustained economic growth (Scottish Government 2007) can be seen to affect some participants' understandings of social inclusion. Gray (2006: 109, 2000) argues that fragmentation and lack of clarity can lead to individualisation in policy content and an increased focus on 'economic rationality'. This was shown in the findings, with participants hinting at economically-based arguments. There was also a tension between participant's understandings of equality of opportunity and income inequality, seen below:

Social inclusion, I suppose it's easy to see when it's not there if you like. I think we have got inequalities, which lead to people becoming alienated from local communities and society in general as they don't have the same amount of opportunities. Or they are isolated because of... Lack of funds or poverty and this drives to sort of a... Underclass almost in society (SNP3).

Evidence suggests that although 'equality of opportunity' rhetoric was dominant among participants, there is an underlying confusion over what this actually stands for - equality, income inequality, poverty, alienation, opportunities or the underclass? The Economic Strategy (Scottish Government 2007) indicates that poverty will be tackled through efforts to reduce income inequality and this objective was also dominant in rhetoric:

So we are zeroing in on income and income inequality in particular. Which is not the same as lifting people out of poverty - it's a slightly different thing... focus on solidarity (CS1).

Again, participants showed tensions within their understandings of how poverty, social inclusion and income inequality were linked. Policy makers had only a general and fragmented understanding of social inclusion. Despite this, the concept is important, part of their ideology and linked to fundamental issues such as poverty and different types of inequality. This is discussed in more detail below. 


\section{Individualisation}

The above evidence shows hints of an increasingly individualised way of looking at the 'socially excluded', with SNP3 mentioning the 'underclass'. Individualistic interpretations of the causes of social exclusion are reflected in some (not all) of the SNP and civil servant dialogue:

But internally, their mental resilience is inhibiting them from dealing with the services that they need to, from being assertive, from having the self confidence and the self esteem to do that. Now as soon as you get into recognising that, you get into a mental wellbeing agenda, which is saying that part of lifting people out of poverty is about increasing their mental wellbeing, and increasing their resilience and so on (CS1, emphasis added).

The participant is mostly referring to an individual's internal coping skills, strength and ability to cope with life and situations such as living in poverty. Using the concept of resilience reflects Scottish Government discussion paper on poverty, inequality and deprivation (2008), and shows a predominantly individualistic view of those classed as socially excluded. This influences how those targeted are viewed, which reflects how policy makers' view the causes of social exclusion. The example above shows 'othering' (Riggins 1997, Lister 1998) and internal barriers to inclusion. This contradicts the original academic understanding of social exclusion and its role in acknowledging the structural causes of poverty with some policy makers resonating with 'the poor do it to themselves' argument as the reason for exclusion (Byrne 1999). The complex and fragmented meanings show that policy makers interpret policy documents and terminology differently, so that documentary definitions alone cannot portray the depth given to concepts and the impact they may have on practice. This evidence suggests that the mixed understandings of policy and the concepts it uses allows individual representations to potentially formulate internal barriers to policy implementation. The following section shows how these individualistic views could impact the role that policy makers' expect of cultural services.

\section{The Role of Culture and Cultural Services}


To understand the role of services within the social inclusion agenda, policy makers' perceptions of culture are explored. Discussing the role of cultural services helps to answer the research question: how do policy makers' perceptions of culture relate to social inclusion policy and the perceived role of cultural services? The following section explores reflective and instrumental ideas of culture (introduced in the literature) and shows how this has affected the role given to cultural services within this more individualistic understanding of the impact of policy.

From policy makers' perspectives, culture, like social inclusion, was inconsistently defined and taken within a wider context including "...all the things around us that make us what we are, but it's also the things that make your life worth living in a sense too" (NL1) and "helps you imagine who you could be, and it helps you understand the world" (CS2). Under these wide, reflective definitions (Hooper-Greenhill 2000), 'culture' was mostly seen as a wide, homogenous concept that can mean anything. It was also seen as a very powerful, all encompassing concept linked with identity and the wellbeing of people in society. Evidence shows that this lack of specific definition has prompted some frustration in the sector:

I think culture, inclusion and social justice and strategy are very, very overworked and sometimes I think misused words. I think probably culture to most people the things that spring to mind are city of culture, opera, drama dance, ballet, art, high culture exactly. Or is it the culture that is all around us, is it being Scottish, being Polish, being Pakistani, Muslim whatever. It is intrinsic to where you come from, your language, your traditions, folklore, heritage, history, the natural world. It's you know, it's everything. I wouldn't want to presume to define that (CB2).

This reflective definition reinforces Belfiore and Bennett's (2007) argument that although there is an implied understanding in the sector, there exist many underlying competing understandings of culture.

\section{Culture as Instrumental}


The vagueness and mixed interpretations of culture and social inclusion lead participants to express their understandings on what they thought cultural services should do. The majority of participants viewed 'culture' as a tool to generate positive outcomes for people in society.

Yeah, culture as action for a better society and in a way that is where this approach [SNP approach] is leading us too (CS1).

But I think that if you can tap into people and use culture as a tool to tap into people's thoughts and, if they are not socially included at the moment, you can sort of find a way to engage with these people to bring them in and make them happier and allow them to have much more positive life. I think without a doubt culture can play a positive role (SNP4).

In considering its role, the study found that policy makers' understanding of culture shifts from an objective, wider definition to a generative, constitutive and actionable concept (HooperGreenhill 2000) that can deliver positive outcomes for the socially excluded. The reflective, wider definition coincides with the UK government's description of culture (Scottish Executive 2000), while the instrumental perceptions link back to using culture as an instrument (HooperGreenhill 2000) that aims to steer behaviours and practices (Clarke 2004). It is this actionable role of culture that aims to utilise cultural services into delivering social policy goals. Gray (2006) discusses that culture is seen as a tool and a resource to be instrumentally for policy agendas. This idea was consistent between MSP's and civil servants and could be explained by the participants' ideas of culture 'generating' positive outcomes (explored in the next section).

However, there was an overall indication that the SNP are retreating from increased ministerial direction to strongly advocating the 'arms-length principle' with cultural services:

The culture minister is taking a much smaller, more lighter touch... taken a step back and said culture is not something you can drive, it's led by its own led policy and we will support it and we can just support it. So I don't think, I wouldn't have said that we could take it, in the way that we use it, as part of an agenda for social change (SNP3). 
This is significant as already this focus has affected changes in the Cultural Bill (Draft 2006) for Scotland, dropping instrumentalist ideas such as cultural entitlements (a non-implemented New Labour policy idea that aimed to give pro-active access to cultural activities such as free opera tickets for children). Despite this suggestion of decreased ministerial intervention in utilizing culture, however, all participants expressed a perceived 'role' for culture. This is linked to their understanding of how individual's can benefit (or benefit themselves) through being included in cultural service provision.

\section{The Role of Cultural Services - Agents of Social Inclusion?}

The idea of culture as reflective or instrumental affects the role that cultural services are perceived to have, which can affect policy targets and outcomes. Within most participants' definitions of culture, related services were mentioned. As participants were talking of cultural services within a social inclusion agenda the idea that services, especially museums, were "agents of social inclusion" (Sandell 1998) was questioned and discussed by all. Interestingly, the concept was more likely to be advocated by political policy makers, but was met with more scepticism by civil servant officers and cultural bodies.

I suppose I would start with what do we mean by social change? And how do we measure it? I would be hesitant to jump in and say that's what we do because I think, we have the potential to inspire and in some ways liberate people from their more formal educational experiences (CB2).

The evidence suggests the idea of cultural services as agents of social change is an appealing concept, but in practice a more difficult thing to achieve. Interestingly, when these particular participants gave their understandings they related them to people's wellbeing, a more individual outcome, rather than be agents of social change.

\section{Generating Wellbeing}

Not many participants thought that cultural services have a fundamental influence on structural social change. Instead, the role of cultural services was set at a much more individual level - a 
level that can help generate people's individual physical, mental, spiritual and intellectual 'wellbeing'.

A lot of people would say if you doing have a kind-of holistic approach to developing an individual through their artistic side as well as through pure income, there is a certain poverty of the spirit perhaps, that that person suffers from, or poverty of wellbeing (CS1).

Because there is a poverty of imagination, and a poverty of aspiration, and a poverty of culture. And the way to break that, I think, as much as it is to boost self confidence and skills through education, is to give them the cultural options to express themselves. To allow them to see themselves as individuals that matter in our society. So I think culture is absolutely crucial (NL2).

This view can be seen to link cultural services to the wider agenda, to use culture to affect individual behaviour and change. The evidence also indicates that policy makers link ideas surrounding social inclusion and cultural services with poverty of 'wellbeing', 'spirit', 'imagination', 'aspiration' and 'culture', not necessarily income poverty. Although the word poverty is used, the context does not reflect the academic meaning of poverty, which focuses on distribution and lack of income (Barry 1998). Instead, policy makers' perspectives on the role of culture reflect the academic definition of social inclusion, which focuses on relational issues and social participation (Room 1995). However, this does not extend to the interlinked agency and structural arguments around the causes. The terms linked to poverty above, such as 'spirit', 'imagination', reflect individualistic characteristics over structural ones encompassed by social exclusion terminology (Byrne 1999), adding to the overall indication of individualist perceptions surrounding the role of social inclusion and cultural services. Thus participants understandings of what causes poverty and exclusion are directly linked to how they view the role and impact that cultural service's can make on individuals. Personal ideology can then be seen to influence policy maker's understandings of cultural policy and its potential outcomes instead of the current policy. Due to the current lack of clarity on concepts and direction for this sector in Scotland, it is unsurprising that policy makers' employ difference mechanisms to explain their views. 


\section{Cultural Services are 'a bit of a bonus'}

The lack of understanding of key concepts can have several impacts on the interpretation and implementation of policy. The lack of policy direction and complexity of cultural concepts has been seen to have the potential to create internal barriers. This fragmentation can create a lack of definitive action in the cultural sector (discussed by Gray 2006). Furthermore, viewing the potential impact of cultural services at an individual level can potentially limit the importance given to cultural services within the policy agenda. Gray (2006) already highlighted that one of the problems of the sector is low political significance and this was reflected here:

... We tend to, tend to slightly push to one side [culture] and get on with the business of government, and the business of living and the business of earning a wage and whatever else. Yet in terms of our wellbeing, our emotional wellbeing, our physical wellbeing I think it is absolutely central (NL2).

The emphasis on culture as a policy makers' rhetoric is high, but in day-to-day parliamentary business, "traditionally the arts is seen to be a bit of a bonus" (CS 1). This argument lowers the priority given to cultural service provision in favour of traditional areas such as employment and housing. Gray (2006) argues that this can then lead to less effort in maintaining direction and control, leading to further fragmentation. This perhaps more than any other reason can explain the lack of policy understanding and coherence within the sector. The challenges to cultural services are all the more potent in a climate where central and governmental cuts are inevitable.

\section{Conclusion}

Scottish policy makers' understandings of culture and social inclusion are generalised, complex and confused. Although social inclusion, poverty and inequality were given priority within rhetoric, policy makers had a wide, varied and fragmented understanding of both social inclusion and culture. The linking of culture to social policy placed culture as a generative and instrumental tool rather than a reflective one, meaning that cultural services can make change, but only on an individual level of wellbeing. This suggests that the role attributed to cultural services was not as a driver of social change but generator of wellbeing. 
The lack of clarity (or perhaps complete lack of) cultural policy in Scotland has influenced policy makers' understandings of culture and the role of cultural services. Scotland's politically driven direction on sustained economic growth has been a key influence in policy makers' understandings, with individualistic explanations of culture and social inclusion becoming dominant. There has also been a shift to a more equity and income inequality based focus. Understandings of poverty, social inclusion, inequality and culture were very confused and linked to more individualistic causes of poverty, with the introduction of concepts such as 'resilience' and 'mental wellbeing'. This idea suggests that individualistic outcomes, rather than structural ones, dominate participant perceptions on the impact of culture.

This then makes the role attributed to cultural services by these policy makers reliant on ideological notions of individual and structural development. Like in Newman and McLean's (2004) findings, policy makers' were quick to advocate the social role of services such as museums, but are unclear as to how they do this or how policy can make this happen. Thus, although culture and social inclusion were often stated as a priority for individuals, it was suggested that cultural services and the arts were "a bit of a bonus", lowering its significance with current policy makers within the Scottish Parliament. 


\section{References}

Baldock, J., Manning, N. and Vickerstaff, S. (2007) (eds) Social Policy, $3^{\text {rd }}$ Ed, Oxford: Oxford University Press,

Barry, B. (2002) 'Exclusion, Isolation and Income', in Hills, J., Le Grand, J. and Piachaud, D. (eds) Understanding Social Exclusion, Oxford: Oxford University Press, pp. 13-29

Barry, M. (1998) 'Social Exclusion and Social Work: An Introduction, in Barry, M. and Hallet, C. (eds) Social Exclusion and Social Work, Issues in Theory, Policy and Practice, Dorset: Russell House Publishing, pp. 1-12

Barry, M. and Hallet, C. (eds) (1998) Social Exclusion and Social Work, Issues in Theory, Policy and Practice, Dorset: Russell House Publishing

Becker, S. and Bryman, A. (2004) Understanding Research for Social Policy and Practice: Themes, Methods and Approaches, Great Britain: The Policy Press

Belfiore, E. and Bennett, O. (2007) 'Rethinking the Social Impacts of the Arts', International Journal of Cultural Policy, 13(2): 135-151

Bochel, H. and Defty, A. (2007) 'MPs' Attitudes to Welfare: A New Consensus? Journal of Social Policy, 36(1): 1-17

Boylan, P. (1988) 'The Changing World of Museums and Art Galleries' in Benington, J. and White, J. (eds) The Future of Leisure Services, Essex: Longman Groups UK Lmt, Chp 5

Byrne, D. (1999) Social Exclusion, Buckingham: Open University Press

Clarke, J. (2004) Changing welfare, changing states: new directions in social policy, London, Sage

Flick, U. (2006) An Introduction to Qualitative Research, $3^{\text {rd }}$ ed, London: Sage Publications

Gray, C. (2000) The Politics of the Arts In Britain, Basingstoke: Macmillan

Gray, C. and Hugoson, R. (2004) 'Culture', in Compston, H. (ed) Handbook of Public Policy in Europe, Basingstoke: Palgrave Macmillan, pp. 365-327

Gray, C. (2006) 'Managing the Unmanageable: The Politics of Cultural Planning', Public policy and Administration, 21(2): 101-113

Gray, C. (2007) 'Commodification and Instrumentality in Cultural Policy', International Journal of Cultural Policy, 13(2): 203-213

Hill, M. (1997), The Policy Process in the Modern State, $3^{\text {rd }}$ Edition, England: Pearson Education Limited

Hooper-Greenhill, E. (2000) Museums and the Interpretation of Visual Culture, Great Britain: Routledge

Hutcheon, P. (2008) SNP dump 'buzz words' in battle against poverty, Sunday Herald, http://www.sundayherald.com/news/heraldnews/display.var.1997266.0.snp dump buzz words in battle against poverty.php, accessed 13/05/08

Lister, R. (1998) 'In from the Margins: Citizenship, Inclusion and Exclusion', in Barry, M. and Hallet, C. (eds) Social Exclusion and Social Work, Issues in Theory, Policy and Practice Dorset: Russell House Publishing, pp. 26-38 
McCall, V. (2009) 'Social Policy and Cultural Services: A Study of Scottish Border Museums as Implementers of Social Inclusion' Social Policy and Society, 8(3): 319-331

Newman, A. and McLean, F. (2004) 'Presumption, Policy and Practice: the Use of Museums and galleries as agents of social inclusion in Great Britain', International Journal of Cultural Policy, 10(2): 167-177

Percy-Smith, J. (ed) (2000), Policy Responses to Social Exclusion: Towards Inclusion? Buckingham: Open University Press.

Riggins, S.H. (ed) (1997) The Language and Politics of Exclusion: Others in Discourse, London: Sage Publications

Room, G. (ed) (1995) Beyond the Threshold, the Measurement and Analysis of Social Exclusion, Great Britain: The Policy Press

Ross, A. (1998) Real Love: In Pursuit of Cultural Justice, London: Routledge

Sandell, R. (1998), 'Museums as Agents of Social Inclusion', Journal of Museum Management and Curatorship, 17(4): 401-418

Sandell, R. (ed) (2002) Museums, Society, Inequality, London and New York: Routledge

Sandell, R. (2003), 'Social Inclusion, the Museum and the Dynamics of Sectoral Change' Journal of Museums and Society, 1(1): 45-62

Scottish Executive. (2000), Creating our Future... Minding our Past, Scotland's National Cultural Strategy, http://www.scotland.gov.uk/nationalculturalstrategy/docs/cult-00.asp?textonly=FALSE, accessed 23/02/09

Scottish Executive. (2001) Creating our Future... Minding our Past, Scotland's National Cultural Strategy First Report, http://www.scotland.gov.uk/Resource/Doc/158792/0043111.pdf, accessed 25/11/08

Scottish Executive. (2002) Creating our Future... Minding our Past, Scotland's National Cultural Strategy Annual Report 2002, http://www.scotland.gov.uk/Publications/2002/11/15764/13298, accessed 25/11/08

Scottish Executive. (2003) Scotland's National Cultural Strategy Annual Report 2003, http://www.scotland.gov.uk/Publications/2003/11/18580/29625, accessed 25/11/08

Scottish Executive. (2006), Draft Culture (Scotland) Bill: Guidance Document, Education Department, http://www.scotland.gov.uk/Publications/2006/12/13092422/0

Scottish Government. (2007) The Government Economic Strategy, http://www.scotland.gov.uk/Resource/Doc/202993/0054092.pdf, accessed 13/05/08

Scottish Government. (2008) Taking Forward the Government Economic Strategy: A Discussion Paper on Tackling Poverty, Inequality and Deprivation in Scotland, http://www.scotland.gov.uk/Publications/2008/02/01150409/18, accessed 13/05/08

Scottish Museums Council. (now Museums Galleries Scotland) (2003) Action Framework does not Address Key Issue, News Archive 2003, www.scottishmuseums.org.uk/news/2003/actionframeworkreply.asp, accessed 15/15/07

Scottish Office. (1999), Social Inclusion -Opening the door to a better Scotland, http://www.scotland.gov.uk/library/documents-w7/sima-00.htm, accessed 15/05/08

Silver, H. (1994) 'Social Exclusion and Social Solidarity: Three Paradigms', International Labour Review, 113(5-6): 531-578

Silverman, D. (2005) Doing Qualitative Research, $2^{\text {nd }}$ ed, London: Sage Publications 
Scullion, A. and Garcia, B. (2005), 'What is Cultural Policy Research?', International Journal of Cultural Policy, 11(2): 113-127

Tlilli, A. (2008) 'Behind the Policy Mantra of the Inclusive Museum: Receptions of Social Exclusion and Inclusion in Museums and Science Centers', Cultural Sociology, 2(1): 123-147

UNESCO. (2002) Universal Declaration on Cultural Diversity, http://www.unesco.org/education/imld 2002/unversal decla.shtml, accessed 08/01/08

Williams, F. (1998) 'Agency and Structure Revisited: Rethinking Poverty and Social Exclusion', in Barry, M. and Hallet, C. (eds) Social Exclusion and Social Work, Issues in Theory, Policy and Practice Dorset: Russell House Publishing, pp. 13-25

West, C. and Smith, C.H.F. (2005), 'We are not a Government Poodle, Museums and Social Inclusion Under New Labour', International Journal of Cultural Policy, 11(3) : 275-288 